\title{
A Conceptual Model of the Challenges of Social Media Big Data for Citizen e-Participation: A Systematic Review
}

\author{
Khulekani Yakobi ${ }^{1(凶)}$ (D), Brenda Scholtz ${ }^{1}$ (D), \\ and Benjamin vom Berg ${ }^{2}$ (D) \\ 1 Nelson Mandela University, Port Elizabeth, South Africa \\ khulekaniy4@gmail.com, brenda.scholtz@mandela.ac.za \\ ${ }^{2}$ University of Applied Science, Bremerhaven, Germany \\ benjamin.wagnervomberg@hs-bremerhaven. de
}

\begin{abstract}
The emergence of Citizen Relationship Management (CzRM) for government plays a central role in developing citizen relationships and e-participation. As such, the South African government has shown its commitment towards citizenry and the provision of effective service delivery. Social Media Analytics (SMA) has emerged as a potential new solution to support decision-making for service delivery in CzRM. It is believed that the demand for SMA adoption will increasingly rise. However, the reality of social media Big Data comes with the challenges of analysing it in a way that brings Big Value. The purpose of this paper is to identify the challenges of social media Big Data Analytics (BDA) and to incorporate these in a conceptual model that can be used by governments to support the e-participation of citizens. The model was developed through a systematic literature review (SLR). The findings revealed that data challenges relate to designing an optimal architecture for analysing data that caters for both historic data and real-time data at the same time. The paper highlight that process challenges relate to all the activities in the data lifecycle such as data acquisition and warehousing; data mining and cleaning; data aggregation and integration; analysis and modelling; and data interpretation. The paper also identifies six types of data management challenges: privacy, security, data governance, data and information sharing, cost/operational expenditures, and data ownership.
\end{abstract}

Keywords: Citizen Relationship Management $\cdot$ Data lifecycle $\cdot$ Big Data $\cdot$ Big Data Analytics · e-Participation · Social Media Analytics

\section{Introduction}

Social Media Analytics (SMA) can provide a decision-making framework that can influence the quality of social media Big Data for citizen e-participation; however, this attempt will need well-defined tools and guidelines for the usage thereof [1]. SMA has also the potential to use advanced techniques to analyse patterns in social media data to enable informed and insightful decision-making for Citizen Relationship Management (CzRM) [2, 3]. CzRM is the growing effort of governments around the world to strive 
to respond rapidly to their citizens by fostering a closer relationship with them, thereby creating more efficient service delivery and e-participation. e-Participation often empowers citizens through social media to act in bottom-up decision-making processes. Information and Communication Technology (ICT) has led to the rise of e-participation, whereby governments adopt digital tools to promote citizen involvement in what is referred to as "CzRM" [4]. Recently, [5] argued that the potential of Big Data for digital tools is often not met since it presents a data set that is so large or complex that it is difficult to process and manage this data using traditional data processing and management applications. The effective and efficient storage and retrieval of vast amounts of structured as well as unstructured data, referred to as Big Data, remains a challenge [6].

The many advantages of social media for government have been highlighted in several studies [7-10]. Some of these advantages are improved service delivery, improved decision-making, transparency, an improved organisation image and more inclusive policy processes. However, $[11,12]$ report that governments lack valid and reliable measures for determining and analysing the effects of social media. Without these measures they remain unable to align their social media initiatives with organisational strategies and ultimately create business value. Several studies [13-15] indicate that the use of social media and ICTs in a government context increases collaboration amongst stakeholders, enabling feedback and promoting citizen e-participation.

Whilst there are a few studies of social media adoption in Africa that show evidence of developing countries joining the social media race [16], there are very few studies reporting on social media Big Data, BDA or SMA in these countries. The most popular social media platforms used in Africa were found to be Twitter and Facebook [17]. Twitter was mostly used for political election campaigns, political movements, strategies for African tourism on cultural heritage, and topic models, while Facebook was mostly used for political revolutions, communication and health delivery.

The main problem identified in this paper is that existing models are more focused on SMA and Big Data Analytics (BDA) in general [18-21] and are not specific to social media BDA (i.e. SMA) for citizen e-participation. They also do not consider the data value chain or the challenges for addressing service delivery and citizen e-participation with social media. There is also a lack of related research in Africa. This gap was addressed by conducting a systematic literature review (SLR) in order to design a conceptual model. The structure of the paper is as follows: Sect. 2 provides an overview of the research question and method adopted in the research. Section 3 reports on review findings: the data lifecycle and SMA challenges. Section 4 reports on discussions and implications for research in Africa. Section 5 concludes the paper and provides an agenda for future possible research.

\section{Research Question and Method}

The research reported on in this paper adopted the SLR approach to answering research questions as proposed by [22]. The SLR will contribute by means of identifying, evaluating and interpreting all available research relevant to the main research question for this study: "What are the challenges of social media Big Data for addressing the 
e-participation of citizens?". The SLR adopted followed the five steps proposed by [23] as shown in Fig. 1. They are: framing questions for a review; identifying relevant work; assessing the quality of studies; summarising the evidence; and interpreting the findings.

\subsection{Framing Questions for a Review}

The problems that were addressed by the review were specified in the form of clear, unambiguous and structured questions before beginning the review work.

\subsection{Identifying Relevant Work}

The search for studies was extensive and multiple sources (both computerised and printed) were searched using keywords including "BDA, social media, SMA". A total of 87 papers were used in this research, however, a total of 54 papers were sampled and selected for more detailed analysis. The study selection criteria flowed directly from the review question. Papers older than seven years were excluded as SMA is a nascent phenomenon in the field of Information Systems.

\subsection{Assessing the Quality of Studies}

In Step 3, the 54 selected studies from Step 2 were subjected to a more refined quality assessment by use of general critical appraisal guides and design-based quality checklists. These assessments were used for exploring heterogeneity and informing decisions regarding suitability of meta-analysis (Step 4).

\subsection{Summarising the Evidence}

Data synthesis consists of tabulation of study characteristics. Therefore, two tables were compiled to achieve this synthesis.

\subsection{Interpreting the Findings}

The findings were interpreted and exploration for heterogeneity helped the research determine whether the overall summary can be trusted, and, where necessary, the effects observed in high-quality studies were used for generating inferences. Any recommendations were graded by reference to the strengths and weaknesses of the evidence. 


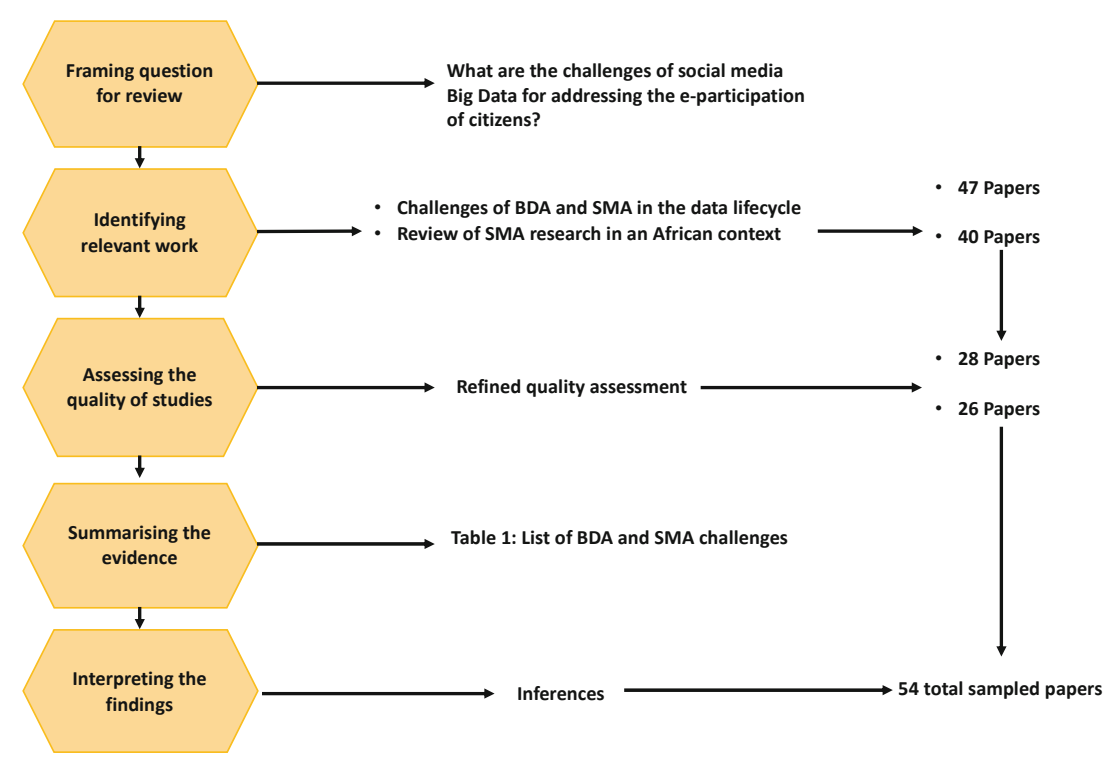

Fig. 1. Adoption of the five comprehensive steps of SLR (Authors' own source)

\section{Review Findings: Data Lifecycle and SMA Challenges}

A study conducted by [24] argues that all data available in the form of Big Data are not useful for analysis or decision-making. For this reason, the challenges of Big Data, with a focus on social media data, were reviewed in the SLR as these challenges might also influence the quality of social media Big Data, which can influence the adoption and success of SMA. These challenges have not yet been adequately addressed [25-28]. The number of studies [29, 30] that have reported challenges of Big Data, do not consider associated challenges related to techniques for data analysis and those related to SMA and BDA. There are limited studies that focus on SMA for government and e-participation. A recent study of Big Data challenges proposed by [28] provided useful insight into the research problem and classified the challenges according to three categories of the data lifecycle. The categories are: Data; Process and Management. The findings of the SLR for this study was classified according to the same three categories and the summary is shown in Table 1. The conceptual model of SMA challenges in the data lifecycle is then illustrated in Fig. 2. 
Table 1. Challenges of BDA and SMA in the data lifecycle

\begin{tabular}{|c|c|c|}
\hline Challenge & Context & Source \\
\hline \multicolumn{3}{|l|}{ Data challenges } \\
\hline $\begin{array}{l}\text { Designing an analytics architecture to cater for } 7 \text { Vs with } \\
\text { legacy databases }\end{array}$ & Big Data & {$[31]$} \\
\hline \multicolumn{3}{|l|}{ Process challenges } \\
\hline Lack of reliable data sources for data collection & Big Data & {$[32,33]$} \\
\hline $\begin{array}{l}\text { Lack of value to service delivery due to unreliable } \\
\text { alignment between social media initiatives and } \\
\text { government strategies }\end{array}$ & $\begin{array}{l}\text { Service Delivery to } \\
\text { citizens; e-participation; } \\
\text { Social media; Government }\end{array}$ & {$[14]$} \\
\hline Lack of fault tolerance techniques & SMA & {$[34,35]$} \\
\hline Visualisation of data & Big Data & {$[35,36]$} \\
\hline \multicolumn{3}{|l|}{ Management challenges } \\
\hline $\begin{array}{l}\text { Data privacy, security and control issues due to } \\
\text { heterogeneous data and data sources }\end{array}$ & Big Data & [37] \\
\hline $\begin{array}{l}\text { The lack of Big Data management presents difficulties } \\
\text { for government to sort this data on privacy levels and to } \\
\text { apply security according to these levels }\end{array}$ & $\begin{array}{l}\text { Big Data; } \\
\text { Government }\end{array}$ & {$[6,33]$} \\
\hline $\begin{array}{l}\text { The lack of Big Data infrastructure has compromised the } \\
\text { security, privacy \& confidentiality of data through } \\
\text { unintended, unauthorised access or inappropriate access } \\
\text { by privileged users }\end{array}$ & Big Data & [38-43] \\
\hline $\begin{array}{l}\text { The lack of data management tools and techniques result } \\
\text { in a negative impact on the decision making process of } \\
\text { government }\end{array}$ & $\begin{array}{l}\text { Government; Decision } \\
\text { making }\end{array}$ & {$[28,44]$} \\
\hline $\begin{array}{l}\text { The lack of Big Data governance causes low levels of } \\
\text { accessibility for SMA }\end{array}$ & SMA & [35] \\
\hline $\begin{array}{l}\text { The lack of data ownership results in the quick spread of } \\
\text { incorrect or false information }\end{array}$ & Big Data & [40] \\
\hline Operational costs \& budget allocations & Decision making & [45] \\
\hline $\begin{array}{l}\text { A lack of skills for SMA \& related tools presents } \\
\text { difficulties for government to interpret data }\end{array}$ & SMA & [46] \\
\hline
\end{tabular}

\subsection{Data Challenges}

Relate to the seven characteristics of the data itself (e.g. volume, velocity, variety, variability, veracity, visualisation and value) [30]; called the 7 'V's of Big Data. These characteristics make the data an unfit candidate to currently employed and tested database architectures [31]. As such, the challenges include capturing, analysis, storage, searching, sharing, visualisation, data transfer and privacy violations, which have been characterised as contributing factors to the 7 'V's [32]. Data challenges relate to designing an optimal architecture for analysing data that caters for both historic data and real-time data at the same time [31, 35]. Legacy database architectures are insufficient. 


\subsection{Process Challenges}

Are related to the series of "how" techniques, which include: how to capture data, how to integrate data, how to transform data, how to select the right model for analysis and how to provide the results [28]. The heterogeneity, scale, timeliness, complexity, and privacy problems with Big Data hamper the progress at all phases of the process that can create value from data [32]. Regardless of where Big Data is generated from and shared to, the lack of analysis techniques results in huge challenges of not capitalising on crucial data which might bring "Big Value" for government [24, 28, 29, 47]. Process challenges relate to all the activities in the data lifecycle such as data acquisition and warehousing; data mining and cleaning; data aggregation and integration; analysis and modelling; and data interpretation. These challenges can therefore be further classified into the phases of the data value chain proposed by [48].

Data acquisition scenarios involves high-volume, high-velocity, high-variety, but low-value data, which makes it important to have adaptable and time-efficient gathering, filtering, and cleaning algorithms that ensure that only the high-value fragments of the data are actually processed by data warehouse analyses [49]. A study conducted by [24] suggest that in order to handle the challenges there is a need to know various computational complexities, information security, and computational methods in order to analyse Big Data. The lack of fault tolerance techniques results in unpredicted failures and compromises data analysis [34, 35].

Organisations are struggling to create business value from social media initiatives since they lack valid and reliable measures for SMA and therefore cannot align these initiatives with organisational strategies [14]. The lack of information on who social media users are, and how they decide what to post online, can contribute to difficulties in confidently interpreting the content of social media posts [46]. Visualisation is needed for intelligence, but this is a challenge since tools lack capacity due to large data sets and the continuous evolving nature of the data. It is presently difficult to recognise interesting patterns and correlations from social media data. The increasing size and number of datasets due to technological advancements in data collection introduces problems of complexity, transparency, integrity and interpretation [50].

\subsection{Management Challenges}

Relate to the tools and techniques needed for effective data management and for obtaining valuable information from voluminous and multifaceted data, which supports decision-making in an organisation [44]. Big Data consists of a large amount of complex data; therefore, it is very difficult for an organization to sort this data on privacy levels and apply security according to these levels [51]. "Big Data is not just about volume and from various sources; it is about its other characteristics such as size, speed of data, structure and quality and new-generation analytic technologies that help organisations get more value from their information assets" [52].

The six types of data management challenges proposed by [28] are: (1) Privacy; (2) Security; (3) Data governance; (4) Data and information sharing; (5) Cost/ operational expenditures; and (6) Data ownership. However, our model incorporates privacy within security as done in [41]. Data and information sharing and ownership 
were grouped together due to the close relationship between these concepts. The resulting model therefore has four types of data management challenges.

Privacy and Security - According to [37], data security and privacy issues can be potentially exasperated by the volume, variety, and wide area deployment of the system infrastructure to support Big Data applications. Social networks are all around us and their popularity is vast. People share a lot of personal information in these networks without any concern for what the organisation behind these networks will do with their data, resulting in a huge threat to our personal privacy [40, 41, 43]. It is not an easy task to address this problem. One suggestion is for new redefined legislation to increase the protection of data privacy. Other have proposed a technique that can be used to increase the control that users have over their own data in social networks, whilst others have recommended distorting the data by adding noise.

According to [38], there is always a possibility of occurrence of security violations by unintended, unauthorised access or inappropriate access by privileged users. As such, securing data from security breaches should be top priority for organisations. IT infrastructure security was particularly highlighted by [41] and [39] as security challenges. IT infrastructure security can be of a major concern since Big Data is a new technology and it may not be understood well by all companies or governments [39, 41]. Integrity and reactive security were emphasised by [42] as challenges related to Big Data. Integrity is the maintenance of the consistency, trustworthiness and accuracy of data and is one of the three dimensions of security (along with confidentiality and availability).

Data Governance - Governments desire data management and information quality, which forms part of data governance [28]. Data governance can be defined as "the processes, policies, standards, organisation and technology required to manage and ensure the availability, accessibility, quality, consistency, auditability and data security in organisations or institutions" [53]. According to [54], "adopting data governance is advantageous, because it is a service based on standardised, repeatable processes and is designed to enable the transparency of data-related processes and cost reduction. It is also useful, because it refers to rules, policies, standards; decision rights; accountabilities and methods of enforcement".

Data and Information Sharing and Ownership - The rising increase of social media has resulted in a new, dynamic form of interpersonal communication globally [55]. It provides users with constant and continuous information sharing, a platform for connecting and collaborating with others and for conveying their thoughts across the world through various mediums; for example, social networking (Facebook), micro-blogging (Twitter, Tumblr), image sharing (Imgur, Flickr) and video hosting and sharing (YouTube, Dailymotion, Vimeo). However, where organisations store large scale datasets, it is an overwhelming task to share and integrate key information across the organisation or between different organisations [28]. The need to share data and information should be balanced and controlled to ensure maximum effect, as this will allow organisations to establish close connections and harmonisation with other stakeholders. 
Cost/Operational Expenditures - Decision makers find it difficult to decide on budget and cost allocation for handling, managing, and analysing Big Data [1].

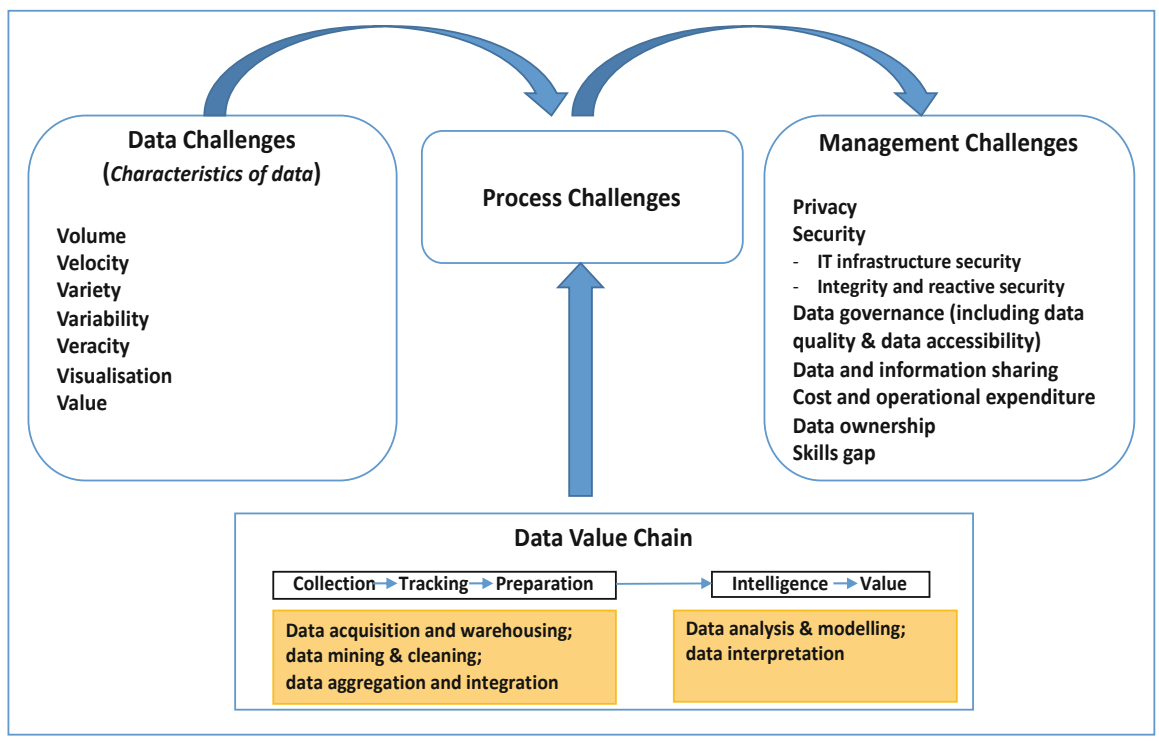

Fig. 2. Model of SMA challenges in the data lifecycle (Authors' own source)

\section{Discussions and Implications for Research in Africa}

In the SLR, only two papers [40, 43] related to challenges in Big Data in Africa. The search was therefore extended to include a review of studies that reported on Big Data or SMA activities occurring in Africa. From this review only 40 papers were identified and only 26 were deemed relevant for a more detailed analysis. A summary of these papers is provided in Appendix A. From this review it is evident that there is a paucity of research related to Big Data and SMA in Africa. This section reflects on these studies in light of the challenges and findings identified in the previous sections.

The study of [56] report that the use of social media by anti- and pro-government groups has been widely publicised, and some suggest that social media was afforded too much credit in the political changes and reforms that occurred in places such as Tunisia, Egypt, Libya, and the ongoing conflict in Syria. The impact of online social media on the voting behavior of the Tunisian voters in the 2014 elections was investigated by [57]. The findings unveiled the debate about the political uses of social networks and their effect on the voting behavior of the Tunisian voters.

A study conducted on Nigeria's general election of 2015 [16] revealed social media as the major influencer and that SMA can contribute in predicting trends that may influence developing economies. On the other hand, the substantial benefits from Big Data and analytics that were reaped by the mobile phone industry in Nigeria [58] 
revealed that proper correlations of social media data can help to reveal more complete and deeper insight of customer needs, thus enriching the operators with more revenue.

A qualitative study done by [40] highlighted the impact of social media as a communication tool, its efficacy and the paradigm change it has brought to the communication process in Namibia. The findings showed that social media challenges were the quick spread of incorrect information as well as compromised security for Internet users. A study showing the role of social media in South Africa explored social media contributions on communication and interaction between health practitioners and patients; this type of ever-growing, social media subscriber-based platform can be of significant use in improving healthcare delivery to society [59]. The study also proposed a framework to guide integration of social media with healthcare Big Data through which service delivery to patients can be improved. The model contributed to healthcare workers' awareness on how social media can possibly be used to improve the services that they provide to the needy. Another study of healthcare Big Data in Morocco [43] also highlighted the privacy challenges in healthcare, mainly related to methods used to ensure the privacy of patient data such as diagnosed diseases, doctor's appointments with patients and prescribed medication.

Furthermore, [60] explored how different features, extracted from social media data, impact the performance of different classifiers of social media in South Africa. The findings revealed that the researchers were able to build models that can classify posts using text features as well as a mixture of text features.

A study showing the role of social media and its impact on the 2011 Egyptian revolution was conducted by [61]. This revolution has often been termed the "Facebook Revolution" or "Twitter Revolution". There are many ambiguities as to the extent to which social media affected these movements. An investigation conducted by [62] aimed to shed some light on the broad characteristics of tweets about African cultural heritage. The findings identified possible implications and strategies for tourism stakeholders in their use of social media in general and Twitter in particular. It was found that tourism stakeholders could use text analysis of publicly available tweet messages to improve tourism. Social media interactions on the financial performance of commercial banks in Kenya was found to offer a platform for marketing and sales of products, development of new product brands and access to real-time customer feedback thereby supporting an enhanced understanding of the needs of their customers [63].

\section{Conclusions and Future Work}

This paper reports on the initial, exploratory phase of a larger, ongoing research project. The aim of the paper was to identify the challenges of social media Big Data and SMA and to propose a model that can provide guidance to practitioners and researchers. If these challenges are addressed, the success of SMA projects can be improved, particularly in government. This classification has three categories, based on the data life cycle, namely: (1) Data; (2) Process; and (3) Management. The challenges of social media Big Data for supporting the context of citizens' e-participation, service delivery and decision making were identified (Table 1). An important contribution of the paper is the extension of the data challenge category to the full data value chain, so as to 
reach the potential Big Value of Big Data (see Fig. 2). The paper also made a contribution to research conducted in Africa.

In Africa there is great potential for using SMA to support decision making and e-participation of citizens. However, many challenges need to be overcome. By addressing the challenges of Big Data and SMA identified in this study (Table 1 and Fig. 2), governments can improve decision making, e-participation and ultimately service delivery to citizens. There is a dire need for additional research on the challenges and future research directions regarding analysing social media Big Data. The novelty of this paper lies in the design and use of a conceptual model for social media Big Data to inform the e-participation of citizens and decision making of management in government. Improved decision-making can assist in a smart city strategy for governments. The study limitation is that it has no empirical evaluation in a practical context as it is based on secondary data from existing literature studies. Future work will include the evaluation of the proposed model.

\section{References}

1. Jukic, T., Merlak, M.: The use of social networking sites in public administration: the case of Slovenia. Electron. J. E-Gov. 15(1), 2 (2017)

2. Gunawong, P.: Open government and social media: a focus on transparency. Soc. Sci. Comput. Rev. 33(5), 587-598 (2015)

3. Kimutai, G.K., Aluvi, P.A.: Good governance and service delivery: a study of citizen participation in Kisumu County. Univers. J. Manag. 6(2), 59-69 (2018). https://doi.org/10. 13189/ujm.2018.060203

4. Zheng, Y., Schachter, H.L.: The impact of administrator willingness on website e-participation: some evidence from municipalities. Public Perform. Manag. Rev. 41(1), $1-21(2018)$

5. Bhadani, A.K., Jothimani, D.: Big data: challenges, opportunities, and realities. In: Effective BD Management and Opportunities for Implementation, pp. 1-24. IGI Global (2016)

6. Mehta, B.B., Rao, U.P.: Privacy preserving unstructured big data analytics: issues and challenges. Procedia Comput. Sci. 78, 120-124 (2016)

7. Bekmamedova, N., Shanks, G.: Social media analytics and business value: a theoretical framework and case study. In: 2014 47th Hawaii International Conference on System Sciences (HICSS), pp. 3728-3737. IEEE (2014)

8. Hussain, A., Vatrapu, R.: Social data analytics tool (SODATO). In: Tremblay, M.C., VanderMeer, D., Rothenberger, M., Gupta, A., Yoon, V. (eds.) DESRIST 2014. LNCS, vol. 8463, pp. 368-372. Springer, Cham (2014). https://doi.org/10.1007/978-3-319-06701-8_27

9. Grubmüller, V., Götsch, K., Krieger, B.: Social media analytics for future oriented policy making. Eur. J. Futures Res. 1(1), 20 (2013)

10. Corrêa, A.S., Paula, E.C.D., Correa, P.L.P., Silva, F.S.C.D.: Transparency and open government data: a wide national assessment of data openness in Brazilian local governments. Transform. Gov.: People Process Policy 11(1), 58-78 (2017)

11. Landon-Murray, M.: Social media and US intelligence agencies: just trending or a real tool to engage and educate? J. Strateg. Secur. 8(3), 67-79 (2015)

12. Verma, R.K., Kumar, S., Ilavarasan, P.V.: Government portals, social media platforms and citizen engagement in India: some insights. Procedia Comput. Sci. 122, 842-849 (2017) 
13. Singh, V., Srivastava, I., Johri, V.: Big data and the opportunities and challenges for government agencies. Int. J. Comput. Sci. Inf. Technol. 5(4), 5821-5824 (2014)

14. Risius, M., Beck, R.: Effectiveness of corporate social media activities in increasing relational outcomes. Inf. Manag. 52(7), 824-839 (2015)

15. Zeng, D., Chen, H., Lusch, R., Li, S.H.: Social media analytics and intelligence. IEEE Intell. Syst. 25(6), 13-16 (2010)

16. Udanor, C., Aneke, S., Ogbuokiri, B.O.: Determining social media impact on the politics of developing countries using social network analytics. Program 50(4), 481-507 (2016)

17. Whillans, A.V., Chen, F.S.: Facebook undermines the social belonging of first year students. Personality Individ. Differ. 133, 13-16 (2018)

18. Lu, Y., et al.: Integrating predictive analytics and social media. In: 2014 IEEE Conference on Visual Analytics Science and Technology (VAST), pp. 193-202. IEEE (2014)

19. Elgendy, N., Elragal, A.: Big data analytics in support of the decision-making process. Procedia Comput. Sci. 100, 1071-1084 (2016)

20. Stieglitz, S., Dang-Xuan, L.: Social media and political communication: a social media analytics framework. Soc. Netw. Anal. Min. 3(4), 1277-1291 (2013). https://doi.org/10. 1007/s13278-012-0079-3

21. Islam, O., Alfakeeh, A., Nadeem, F.: A framework for effective big data analytics for decision support systems. Int. J. Comput. Netw. Appl. (IJCNA) 4(5), 129-137 (2017). https://doi.org/10.22247/ijcna/2017/49227

22. Higgins, J.P., Thompson, S.G., Deeks, J.J., Altman, D.G.: Measuring inconsistency in metaanalyses. BMJ 327(7414), 557-560 (2003)

23. Khan, K.S., Kunz, R., Kleijnen, J., Antes, G.: Five steps to conducting a systematic review. J. R. Soc. Med. 96(3), 118-121 (2003)

24. Acharjya, D.P., Ahmed, K.: A survey on big data analytics: challenges, open research issues and tools. Int. J. Adv. Comput. Sci. Appl. 7(2), 511-518 (2016)

25. Adrian, C., Abdullah, R., Atan, R., Jusoh, Y.Y.: Conceptual model development of big data analytics implementation assessment effect on decision-making. Technology 23, 24 (2018)

26. Gupta, M., George, J.F.: Toward the development of a big data analytics capability. Inf. Manag. 53(8), 1049-1064 (2016)

27. Lee, I.: Big data: dimensions, evolution, impacts, and challenges. Bus. Horiz. 60(3), 293303 (2017)

28. Sivarajah, U., Kamal, M.M., Irani, Z., Weerakkody, V.: Critical analysis of BD challenges and analytical methods. J. Bus. Res. 70, 263-286 (2017)

29. Fan, J., Han, F., Liu, H.: Challenges of big data analysis. Natl. Sci. Rev. 1(2), 293-314 (2014)

30. Rajaraman, V.: Big data analytics. Resonance 21(8), 695-716 (2016)

31. Uddin, M.F., Gupta, N.: Seven V's of big data understanding big data to extract value. In: Proceedings of the 2014 Zone 1 Conference of the American Society for Engineering Education, pp. 1-5. IEEE (2014)

32. Anuradha, J.: A brief introduction on big data 5Vs characteristics and Hadoop technology. Procedia Comput. Sci. 48, 319-324 (2015)

33. Khan, N., et al.: Big data: survey, technologies, opportunities, and challenges. Sci. World J. 2014, 18 (2014)

34. Ganesh, A., Sandhya, M., Shankar, S.: A study on fault tolerance methods in cloud computing. In: 2014 IEEE International Advance Computing Conference (IACC), pp. 844849. IEEE (2014)

35. Mishra, S., Dhote, V., Prajapati, G.S., Shukla, J.P.: Challenges in big data application: a review. Int. J. Comput. Appl. 121(19) (2015) 
36. Ali, A., Qadir, J., ur Rasool, R., Sathiaseelan, A., Zwitter, A., Crowcroft, J.: Big data for development: applications and techniques. Big Data Anal. 1(1), 2 (2016)

37. Moura, J., Serrão, C.: Security and privacy issues of big data. In: Handbook of Research on Trends and Future Directions in Big Data and Web Intelligence, pp. 20-52. IGI Global (2015)

38. Jaseena, K.U., David, J.M.: Issues, challenges, and solutions: big data mining. Comput. Sci. Inf. Technol. (CS \& IT) 4, 131-140 (2014)

39. Kanchi, S., Sandilya, S., Ramkrishna, S., Manjrekar, S., Vhadgar, A.: Challenges and solutions in big data management-an overview. In: 2015 3rd International Conference on Future Internet of Things and Cloud, pp. 418-426. IEEE (2015)

40. Matali, M.: An investigation of the impact of social media as an effective communication tool in Namibia: a case study of the Affirmative repositioning Movement (ARM). Doctoral dissertation, University of Namibia (2017)

41. Moreno, J., Serrano, M.A., Fernández-Medina, E.: Main issues in big data security. Future Internet 8(3), 44 (2016)

42. Sari, A., Karay, M.: Reactive data security approach and review of data security techniques in wireless networks. Int. J. Commun. Netw. Syst. Sci. 8(13), 567 (2015)

43. Mounia, B., Habiba, C.: Big data privacy in healthcare Moroccan context. Procedia Comput. Sci. 63, 575-580 (2015)

44. Bagga, S., Sharma, A.: Big data and its challenges: a review. In: 2018 4th International Conference on Computing Sciences (ICCS), pp. 183-187. IEEE (2018)

45. Baraka, Z.: Opportunities to manage big data efficiently and effectively. Doctoral dissertation, Dublin Business School (2014)

46. Lopez, B.E., Magliocca, N.R., Crooks, A.T.: Challenges and opportunities of social media data for socio-environmental systems research. Land 8, 107 (2019). https://doi.org/10.3390/ land 8070107

47. Khatana, P., Soni, Y.: Big data techniques: today and tomorrow. Int. J. Res. Eng. Sci. Manag. 1(11), 282-284 (2018)

48. Abadi, M., et al.: TensorFlow: large-scale machine learning on heterogeneous distributed systems. arXiv preprint arXiv:1603.04467 (2016)

49. Lyko, K., Nitzschke, M., Ngonga Ngomo, A.-C.: Big data acquisition. In: Cavanillas, J.M., Curry, E., Wahlster, W. (eds.) New Horizons for a Data-Driven Economy, pp. 39-61. Springer, Cham (2016). https://doi.org/10.1007/978-3-319-21569-3_4

50. Specht, A., et al.: Data management challenges in analysis and synthesis in the ecosystem sciences. Sci. Total Environ. 534, 144-158 (2015)

51. Ularu, E.G., Puican, F.C., Apostu, A., Velicanu, M.: Perspectives on big data and big data analytics. Database Syst. J. 3(4), 3-14 (2012)

52. Saleh, S.H., Ismail, R., Ibrahim, Z., Hussin, N.: Issues, challenges and solutions of big data in information management: an overview. Int. J. Acad. Res. Bus. Soc. Sci. 8(12) (2018)

53. Putro, B.L., Surendro, K., Herbert: Leadership and culture of data governance for the achievement of higher education goals (case study: Indonesia University of Education). In: AIP Conference Proceedings, vol. 1708, no. 1, p. 050002. AIP Publishing (2016)

54. Koltay, T.: Data governance, data literacy and the management of data quality. IFLA J. 42(4), 303-312 (2016)

55. Curry, E.: The big data value chain: definitions, concepts, and theoretical approaches. In: Cavanillas, J.M., Curry, E., Wahlster, W. (eds.) New Horizons for a Data-Driven Economy, pp. 29-37. Springer, Cham (2016). https://doi.org/10.1007/978-3-319-21569-3_3

56. Biswas, M., Sipes, C.: Social media in Syria's uprising and post-revolution Libya: an analysis of activists' and Blogger's online engagement. Arab Media Soc. 19, 1-21 (2014) 
57. Kavanaugh, A., Sheetz, S.D., Skandrani, H., Tedesco, J.C., Sun, Y., Fox, E.A.: The use and impact of social media during the 2011 Tunisian revolution. In: Proceedings of the 17th International Digital Government Research Conference on Digital Government Research, pp. 20-30. ACM (2016)

58. Nwanga, M.E., Onwuka, E.N., Aibinu, A.M., Ubadike, O.C.: Impact of big data analytics to Nigerian mobile phone industry. In: 2015 International Conference on Industrial Engineering and Operations Management (IEOM), pp. 1-6. IEEE (2015)

59. Mgudlwa, S., Iyamu, T.: Integration of social media with healthcare big data for improved service delivery. S. Afr. J. Inf. Manag. 20(1), 1-8 (2018)

60. Marivate, V., Moiloa, P.: Catching crime: detection of public safety incidents using social media. In: 2016 Pattern Recognition Association of South Africa and Robotics and Mechatronics International Conference (PRASA-RobMech), pp. 1-5. IEEE (2016)

61. Chebib, N.K., Sohail, R.M.: The reasons social media contributed to the 2011 Egyptian revolution. Int. J. Bus. Res. Manag. (IJBRM) 2(3), 139-162 (2011)

62. Alemneh, D.G., Rorissa, A., Assefa, S.: Harnessing social media for promoting tourism in Africa: an exploratory analysis of tweets. In: IConference 2016 Proceedings (2016)

63. Njeri, M.W.: Effect of social media interactions on financial performance of commercial banks in Kenya. M.Sc. project, University of Nairobi, Kenya (2014) 